\title{
Biodegradation of Aged Residues of Atrazine and Alachlor in a Mix-Load Site Soil by Fungal Enzymes
}

\author{
Anastasia E. M. Chirnside, ${ }^{1}$ William F. Ritter, ${ }^{1}$ and Mark Radosevich ${ }^{2}$ \\ ${ }^{1}$ Bioresources Engineering, University of Delaware, Townsend Hall, Rm 264, 531 S. College Ave, Newark, DE 19716-2140, USA \\ ${ }^{2}$ Biosystems Engineering and Soil Science, University of Tennessee, 2506 E.J. Chapman Dr., Knoxville, TN 37996-4531, USA
}

Correspondence should be addressed to Anastasia E. M. Chirnside, aemc@udel.edu

Received 14 April 2011; Revised 22 July 2011; Accepted 24 July 2011

Academic Editor: Teodoro Miano

Copyright (C) 2011 Anastasia E. M. Chirnside et al. This is an open access article distributed under the Creative Commons Attribution License, which permits unrestricted use, distribution, and reproduction in any medium, provided the original work is properly cited.

\begin{abstract}
Soils from bulk pesticide mixing and loading (mix-load) sites are often contaminated with a complex mixture of pesticides, herbicides, and other organic compounds used in pesticide formulations that limits the success of remediation efforts. Therefore, there is a need to find remediation strategies that can successfully clean up these mix-load site soils. This paper examined the degradation of atrazine (2-chloro-4-ethylamino-6-isopropylamino-S-triazine; AT) and alachlor (2-chloro-2', 6'-diethyl-N[methoxymethyl]-acetanilide) in contaminated mix-load site soil utilizing an extracellular fungal enzyme solution derived from the white rot fungus, Phanerochaete chrysosporium, grown in a packed bed bioreactor. Thirty-two percent of AT and 54\% of AL were transformed in the biometers. The pseudo first-order rate constant for AT and AL biodegradation was $0.0882 \mathrm{~d}^{-1}$ and $0.2504 \mathrm{~d}^{-1}$, respectively. The half-life $\left(t_{1 / 2}\right)$ for AT and AL was 8.0 and 3.0 days, respectively. Compared to AT, the initial disappearance of AL proceeded at a faster rate and resulted in a greater amount of $\mathrm{AL}$ transformed. Based on the net $\mathrm{Co}_{2}$ evolved from the biometers, about $4 \%$ of the AT and AL initially present in the soil was completely mineralized.
\end{abstract}

\section{Introduction}

Bulk pesticide mixing and loading (mix-load) sites are major contributors of pesticide contamination of ground and surface waters [1]. Many of these sites contain extremely high concentrations of pesticides, fertilizers, and other organic compounds used in pesticide formulations, which may limit bioremediation efforts due to the toxicity effects of the high pesticide concentrations to the indigenous microbes $[2,3]$, the complexity of the mixture of compounds present [4], and the natural heterogeneity of the soil and water environment [5]. Remediation treatment strategies must evaluate and overcome the difficulties associated with mix-load sites.

Bioaugmentation has become a cost-effective alternative for cleanup of contaminated soil and groundwater. Although bacterial degradation schemes are utilized more often, there is great potential for the use of fungal degradative systems. Certain fungi, particularly the white rot fungi (WRF), are often more successful degrading pesticides than other microorganisms because of their ability to tolerate and/or detoxify pesticides found in complex mixtures and at high concentrations, such as those soils from mix-load sites [4].

The WRF, Phanerochaete chrysosporium, has been shown to degrade a variety of pesticides in the laboratory. However, field applications have not had as much success due to the difficulties with growing the fungi to sufficient biomass for soil application. The complex interactions among fungal inoculant, soil type, and soil microflora have led to failure of field scale experiments [6, 7]. Several studies have seen competition by indigenous organisms during degradation while other studies have isolated microbes from the soil that are antagonistic to P. chrysosporium $[4,7]$.

The ligninolytic growth phase of WRF produces peroxidases, lactases, laccases, hydrogen peroxide-generating systems, other enzymes, and cofactors $[4,6,8]$ that are capable of degrading recalcitrant compounds. Because of the extracellular nature of these ligninolytic enzymes, researchers investigated the potential of utilizing the fungal enzyme solution directly in the contaminated soil. Rodríguez-Couto et al. [9] successfully decolorized the polymeric dye, Roly R-478, 
in aqueous cultures using the extracellular culture fluid that contained primarily LiP from a semisolid state bioreactor of $P$. chrysosporium. In another study with P. chrysosporium, ligninolytic enzymes separated from mycelia were able to continue bleaching hardwood kraft pulp for 5 days [10]. These successes have confirmed that the extracellu-lar enzymes of the WRF can be active in soil.

A contaminated soil from a 100-year-old mix-load site located in Reading, Pa was found to contain high concentrations of pesticides and fertilizers [11]. Soil concentrations of atrazine (2-chloro-4-ethylamino-6-isopropylaminoS-triazine; AT) and alachlor (2-chloro-2', $6^{\prime}$-diethyl-N-[methoxymethyl]-acetanilide; AL) were above the EPA riskbased concentrations (RBC) for commercial areas [12], with $52 \mathrm{mg} \mathrm{kg}^{-1}$ AT $\left(\mathrm{RBC}=13.0 \mathrm{mg} \mathrm{kg}^{-1}\right)$ and $200 \mathrm{mg} \mathrm{kg}^{-1} \mathrm{AL}$ $\left(\mathrm{RBC}=36.0 \mathrm{mg} \mathrm{kg}^{-1}\right)$. The purpose of this paper was to develop a feasible bioremediation technique for the contaminated mix-load site soil utilizing the unique ligninolytic system of the WRF. Specifically, the objective of this research was to examine the degradation of AT and AL in both aqueous batch microcosms and in the contaminated mixload site soil utilizing the fungal extracellular enzyme solution (EES) derived from the white rot fungus, Phanerochaete chrysosporium.

\section{Materials and Methods}

2.1. Enzyme Inoculum Preparation. Production of the ligninolytic enzymes was achieved by growing fungal cultures in a packed bed bioreactor (PBR) operated in semicontinuous mode based on the methods of Feijoo et al. [13]. Phanerochaete chrysosporium cultures (ATCC \#34541) were maintained on $2 \%$ malt agar slants at ambient temperature. In preparation for spore production, the fungal cultures were transferred to petri dishes containing the $2 \%$ malt agar and incubated for two to five days at $39^{\circ} \mathrm{C}$ following the procedure of Tien and Kirk [14]. The harvested conidia $(10 \mathrm{~mL}, \mathrm{~A} 650=0.18)$ were utilized for mycelia production in shallow stationary cultures containing $75 \mathrm{~mL}$ of growth media. The flasks were maintained at $37^{\circ} \mathrm{C}$ and gently flushed with $100 \%$, filter-sterilized ( 0.2 um) oxygen ( $98 \%$ Purity; 0.5 bars) for 5 minutes every day. After sufficient growth, the mycelia were harvested, homogenized, and then immobilized onto polyurethane foam cubes $\left(1 \mathrm{~cm}^{3}, \rho=354 \mathrm{~kg} \mathrm{~m}^{-3}\right)$ following the procedures of Feijoo et al. [13].

The jacketed PBR was heated by pumping water $\left(37^{\circ} \mathrm{C}\right)$ through the column. Filter-sterilized $(0.2 \mu \mathrm{m})$, high purity oxygen was purged $(0.5 \mathrm{bar})$ through the column to maintain aerobic conditions. Flow was produced by peristaltic pumps (Model 77120-30) with an influent flow rate of $0.4 \mathrm{~mL} \mathrm{~min}^{-1}$ and a recycle flow rate of $0.7 \mathrm{~mL} \mathrm{~min}^{-1}$ resulting in a hydraulic retention time of approximately 8 hours. The polyurethane foam cubes containing immobilized $P$. chrysosporium were aseptically transferred to the $200 \mathrm{~mL}$ working volume of the bioreactor. After sufficient growth was achieved in the PBR, the influent was switched to a nitrogen-limiting media to induce ligninolytic activity, and the overflow effluent was monitored for LiP and MnP production.
Lignin peroxidase activity was determined by measuring the oxidation of veratryl alcohol (VA) to veratraldehyde at $310 \mathrm{~nm}\left(\varepsilon=9,300 \mathrm{M}^{-1} \mathrm{~cm}^{-1}\right)$ [14]. The reaction mixture contained $0.2 \mathrm{~mL} 10 \mathrm{mM}$ VA; $0.2 \mathrm{~mL} 0.25 \mathrm{M}$ d-tartaric acid, $\mathrm{pH} 2.5 ; 0.08 \mathrm{~mL} \mathrm{H}_{2} \mathrm{O}_{2}$ (30\%); $0.520 \mathrm{~mL}$ of collected bioreactor effluent manganese-dependent peroxidase activity was determined by the oxidation of o-dianisidine $(-2 \mathrm{HCl})$ at $460 \mathrm{~nm}\left(\varepsilon=29,400 \mathrm{M}^{-1} \mathrm{~cm}^{-1}\right)$ [15]. The reaction mixture contained $0.1 \mathrm{~mL} 1 \mathrm{mM}$ manganese sulfate; $0.2 \mathrm{~mL} 0.5 \mathrm{M}$ sodium tartrate, pH 5.0; $0.1 \mathrm{~mL} 1 \mathrm{mM} \mathrm{H}_{2} \mathrm{O}_{2} ; 0.1 \mathrm{~mL} 1 \mathrm{mM}$ o-dianisidine; $0.500 \mathrm{~mL}$ of collected bioreactor effluent.

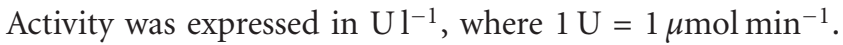
The extracellular enzyme solution (EES) used for the degradation studies contained 149.0 $\mathrm{U} \mathrm{l}^{-1} \mathrm{LiP}$ and $77.6 \mathrm{U} \mathrm{l}^{-1} \mathrm{MnP}$.

2.2. AT and AL Biodegradation in Aqueous Cultures. Standard aqueous cultures containing selective media (AT and AL as the only source of carbon and nitrogen) were utilized to evaluate the catalytic activity of the EES. The microcosms consisted of $250 \mathrm{~mL}$ Erlenmeyer flasks containing $50 \mathrm{~mL}$ of the selective herbicide solution with $27.0 \mathrm{mg} \mathrm{L}^{-1} \mathrm{AT}$, $21.16 \mathrm{mg} \mathrm{L}^{-1} \mathrm{AL}, 0.5 \mathrm{~mL}$ concentrated phosphate buffer $(\mathrm{pH}$ $6.8), 0.5 \mathrm{~mL}$ concentrated salt solution, and $0.5 \mathrm{~mL}$ trace elements [1]. The following three treatments were evaluated: (1) $5 \mathrm{~mL}$ of the collected enzyme solution, (2) $5 \mathrm{~mL}$ of the collected enzyme solution and $1 \mathrm{~mL} 5 \mathrm{mM} \mathrm{H}_{2} \mathrm{O}_{2}$, and (3) $5 \mathrm{~mL}$ of sterilized distilled deionized water (DDW) and $1 \mathrm{~mL}$ $5 \mathrm{mM} \mathrm{H}_{2} \mathrm{O}_{2}$ as the control. The flasks were sampled on days $0,1,2,5,7,9$, and 10 . Prior to sampling the flasks were weighed and corrected for evaporative water loss by addition of sterile water. A $0.5 \mathrm{~mL}$ aliquot was removed and mixed with $0.5 \mathrm{~mL}$ acetonitrile and centrifuged at approximately $12,000 \times \mathrm{g}$ for 10 minutes. The supernatant was transferred to HPLC vials for analysis.

2.3. AT and AL Biodegradation in Soil Microcosms. Aerobic microcosms were prepared in standard $250 \mathrm{~mL}$ biometer flasks (Bellco, Glass Inc., Vineland, NJ) consisting of a main body with a side-arm trap containing $0.2 \mathrm{~N} \mathrm{NaOH}$ prepared with $\mathrm{CO}_{2}$-free DDW. Fifty grams of air-dried, ground soil collected from a 100-year-old mix-load site located in Reading, $\mathrm{Pa}$ [1] were placed into the main body of the biometer flasks. Site $5 \mathrm{~A}$ soil was chosen for this study because of the lack of AT and AL degraders [1] and the presence of high concentrations AT and AL (Table 2). The flasks were autoclaved at $120^{\circ} \mathrm{C}$ (290 bar) on three consecutive days before treatment. Three control flasks received $5 \mathrm{~mL}$ of sterile DDW and $1 \mathrm{~mL} 5 \mathrm{mM} \mathrm{H}_{2} \mathrm{O}_{2}$. The 3 treatment flasks received $5 \mathrm{~mL}$ of the EES collected from the PBR as described previously. Before addition to the biometers, the treatment solution (EES or DDW) and the $\mathrm{H}_{2} \mathrm{O}_{2}$ were mixed well for $30 \mathrm{sec}$ and then added to the flasks. Biometer flasks were incubated at $23^{\circ} \mathrm{C}$ for the length of the experiment. The biometers were monitored for AT, AL, and metabolites. The entire experiment was done in triplicate.

The biometer flasks were monitored for $\mathrm{CO}_{2}$ and herbicide concentration on days $1,2,3,4,7$, and 13 . The $\mathrm{NaOH}$ in the biometer side-arm traps was extracted and analyzed 
TABLE 1: A list of the compounds monitored by HPLC and \% recovery at the $95 \%$ level of confidence. All compounds were purchased from ChemService, Inc. (West Chester, Pa) and used as received.

\begin{tabular}{lcc}
\hline & Label & $\%$ Recovery \\
\hline Atrazine & CIET & $100.5 \pm 5.8$ \\
Atrazine deethyl & CIAT & $38.2 \pm 3.2$ \\
Atrazine deethyl-2-hydroxy & OIAT & $8.04 \pm 2.4$ \\
Atrazine-2-hydroxy & OIET & $8.00 \pm 1.7$ \\
Atrazine deethyl deisopropyl-2-hydroxy & OAAT & $23.8 \pm 7.9$ \\
Atrazine deethyl deisopropyl & CAAT & $24.8 \pm 6.4$ \\
Atrazine deisopropyl & CEAT & $16.3 \pm 1.8$ \\
Alachlor & AL & $97.1 \pm 8.7$ \\
2-chloro-2',6'-diethylacetamilide & DMA & $100.6 \pm 9.2$ \\
2,6-diethylanaline & DIE & $50.1 \pm 7.4$ \\
Cyanazine & CY & $87.6 \pm 5.4$ \\
Metolachlor & ME & $84.6 \pm 6.5$ \\
Simazine & SI & $86.4 \pm 7.6$ \\
Simazine hydroxy & SIOH & $44.02 \pm 11$ \\
Aniline & ANI & \\
\hline
\end{tabular}

TABle 2: Physical and chemical properties of Site 5A soil (dry wt. basis).

\begin{tabular}{lc}
\hline Sample & $\mathrm{S}-5 \mathrm{~A}$ \\
\hline Location & East side of loading dock \\
Textural class & loamy sand \\
$\mathrm{SOM} \%$ & $1.1(0)^{\mathrm{a}}$ \\
$\mathrm{pH}$ & 7.33 \\
$\mathrm{NH}_{4}-\mathrm{N}\left(\mathrm{mg} \mathrm{kg}^{-1}\right)$ & $10.49(0.31)$ \\
$\mathrm{NO}_{3}-\mathrm{N}\left(\mathrm{mg} \mathrm{kg}^{-1}\right)$ & $50.24(3.12)$ \\
Sol Salts $\left(\mathrm{mmho} \mathrm{cm}^{-1}\right)$ & $1.34(0.11)$ \\
Acidity $\left(\mathrm{meq} 00 \mathrm{~g}^{-1}\right)$ & $0.033(0.029)$ \\
Moisture content, field capacity $(\%)$ & 8.61 \\
Atrazine $\left(\mathrm{mg} \mathrm{kg}^{-1}\right)$ & $205.1(10.2)$ \\
Alachlor $\left(\mathrm{mg} \mathrm{kg}^{-1}\right)$ & $108.5(8.3)$ \\
Cyanazine $\left(\mathrm{mg} \mathrm{kg}^{-1}\right)$ & $2272.3(145.5)$ \\
Simazine $\left(\mathrm{mg} \mathrm{kg}^{-1}\right)$ & $13.15(1.94)$ \\
Metolachlor $\left(\mathrm{mg} \mathrm{kg}^{-1}\right)$ & $1829.4(106.4)$ \\
\hline
\end{tabular}

${ }^{a}$ Number in parentheses represents standard deviation of 3 values.

for $\mathrm{CO}_{2}$ by the traditional acid titration method outlined by Zibilske [16]. Approximately $1 \mathrm{~g}$ aliquots of soil were removed from the flasks for herbicide determination.

2.4. Herbicide Analysis. The soils were analyzed for AT, $\mathrm{AL}$, and metabolites using a solid-phase extraction (SPE) method followed by HPLC analysis [17]. The solid-phase extraction method was modified in order to extract possible polar metabolites. The $1 \mathrm{~g}$ soil aliquots were extracted with $50 \mathrm{~mL} 90 \%$ methanol and centrifuged $(2400 \mathrm{~g} \times \mathrm{rpm})$ for 20 minutes. A $5 \mathrm{~mL}$ aliquot of the supernatant was diluted with $55 \mathrm{~mL}$ DDW before SPE. Solid-phase extraction of the diluted aliquots was performed following the method of
Chirnside et al. [11]. The resulting elutant was evaporated to dryness, redissolved with $5 \mathrm{~mL}$ acetonitrile, and transferred to HPLC vials for analysis.

A $20 \mu \mathrm{L}$ aliquot of the prepared samples was analyzed with a Thermo Separations Product-AS3000 Series HPLC equipped with a UV photodiode array detector set at $220 \mathrm{~nm}$ and the reversed phase Phenomenex Synergi $4 \mu$ Polar-RP column $(150 \times 4.6 \mathrm{~mm}, \mathrm{dp}=4 \mu \mathrm{m})$ set at ambient temperature. A gradient mobile phase consisting of (a) acetonitrile and (b) $0.003 \mathrm{M}$ potassium dihydrogen phosphate, $\mathrm{pH}=$ 3.00 was used. Percent recoveries of AT, AL, and metabolites were determined by replicate analysis of reference soil spikes (Table 1).

\section{Results}

3.1. AT and AL Biodegradation in Aqueous Cultures. There was an immediate decrease in both AT and AL concentration for both treatments (Figure 1). There was about a 10- to15-minute period between the two tasks of adding the EES to the flasks and removing the aliquot for analysis. The enzymatic reactions progressed immediately within the treatment flasks. The initial AT and AL concentration in all flasks was approximately $29 \pm 1.21 \mathrm{mg} \mathrm{L}^{-1}(0.1351 \mathrm{mM})$ and $189 \pm 2.96 \mathrm{mg} \mathrm{L}^{-1}(0.6995 \mathrm{mM})$, respectively. Both of the treatments showed a further decrease in AT and AL concentration during the test period. Treatment 2 (enzyme plus hydrogen peroxide) resulted in the greatest decrease in concentration with $14.4 \%$ of the AT $(0.0983 \mathrm{mM}, \mathrm{d} 10)$ and $15.9 \%$ of the AL $(0.5880 \mathrm{mM}, \mathrm{d} 10)$ transformed. Treatment 1 resulted in a $12.1 \%(0.1188 \mathrm{mM}, \mathrm{d} 10)$ and $11.4 \%$ $(0.6195 \mathrm{mM}$ at d 10) reduction of AT and AL, respectively.

Only very low levels of atrazine metabolites were produced in Treatment 1 flasks (Figure 2). The deisopropylatrazine (CEAT) metabolite was detected on day 0 but 


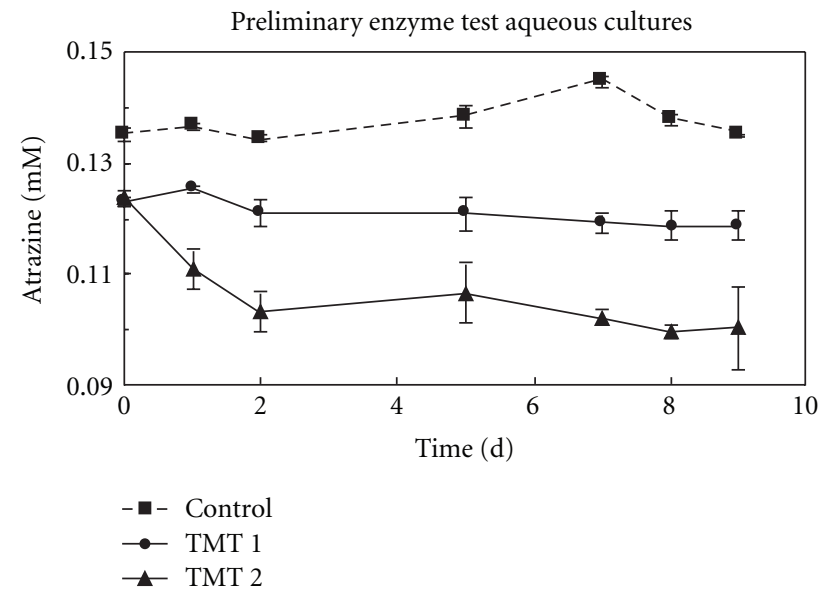

(a)

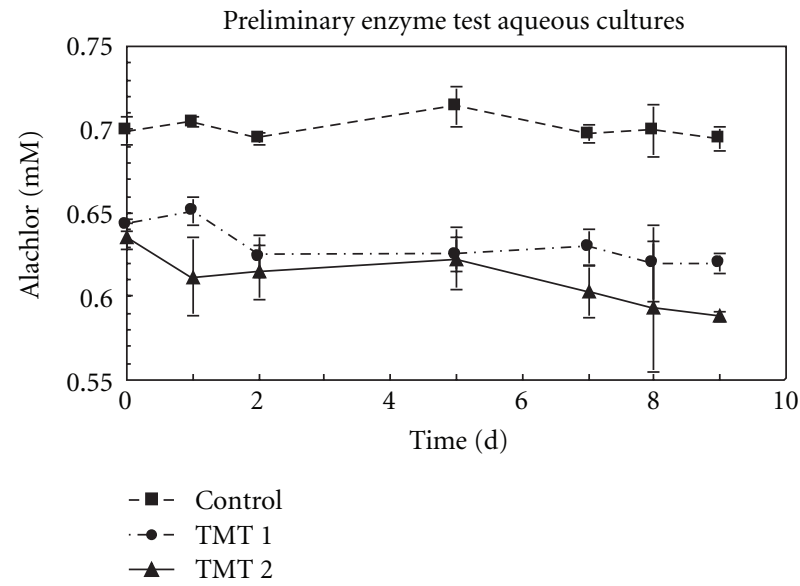

(b)

FIgUre 1: Disappearance of AT and AL from aqueous cultures treated with the EES. Treatment 1 consisted of the addition of the EES only, while Treatment 2 consisted of the addition of the EES and $\mathrm{H}_{2} \mathrm{O}_{2}$. (a) AT degradation among treatments. (b) AL degradation among treatments. Control consisted of DDW and $\mathrm{H}_{2} \mathrm{O}_{2}$.

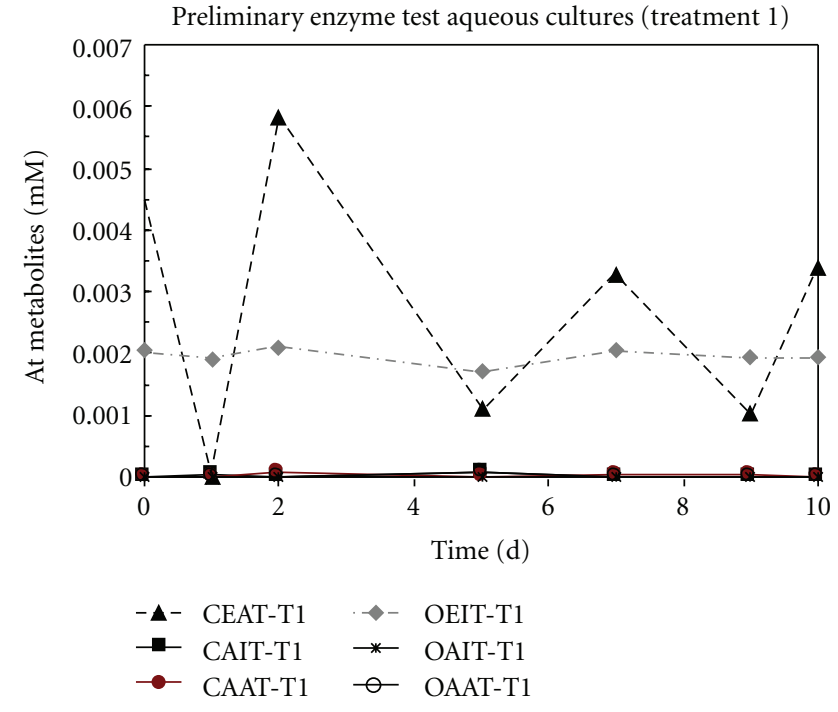

(a)

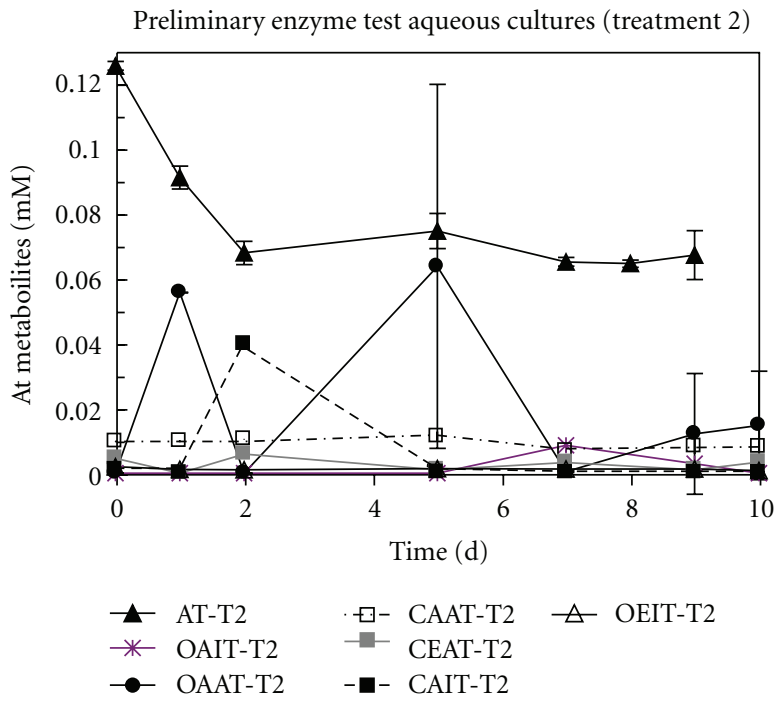

(b)

FIGURE 2: Production of atrazine metabolites during preliminary enzyme test in aqueous cultures. (a) Treatment 1 (EES only). (b) Treatment $2\left(\right.$ EES and $\left.\mathrm{H}_{2} \mathrm{O}_{2}\right)$. OIET = atrazine-2-hydroxy, CAAT = atrazine deethyl deisopropyl, OAAT = atrazine deethyl deisopropyl-2-hydroxy, CEAT $=$ atrazine deisopropyl, OIAT $=$ atrazine deethyl-2-hydroxy.

was completely transformed the following day. The level increased again and was further transformed throughout the test period. Hydroxyatrazine (OEIT) was seen on day 0 but the concentration remained the same throughout the incubation. In Treatment 2, a low level of the bis-dealkylated metabolite (CAAT) was seen on day 0 and remained constant throughout the incubation period. The dechlorinated bisdealkylated metabolite (OAAT) was detected on day 1. It was further degraded, but more OAAT was seen on day 5. Again, the OAAT was further degraded with very little remaining at the end of the incubation period. As in Treatment 1, the double dealkylated metabolite (CAAT) was present at a constant low concentration throughout the experiment.
Figure 3 illustrates the production of the two alachlor metabolites, DMA and DIE, for both Treatment 1 and Treatment 2. Both treatments produced very low concentrations of DMA. The aniline metabolite (DIE) was only present at low concentrations in Treatment 2.

\subsection{AT and AL Biodegradation in Soil Microcosms}

3.2.1. $\mathrm{CO}_{2}$ Evolution Rates. A steady increase in $\mathrm{CO}_{2}$ evolution was seen for both treatments (Figure 4). However, the $\mathrm{CO}_{2}$ evolution in the treated biometers increased at a rate approximately two times greater than the background $\mathrm{CO}_{2}$ of the untreated biometers $\left(0.0400 \mathrm{mM} \mathrm{CO}_{2} \mathrm{~d}^{-1}\right.$ versus 


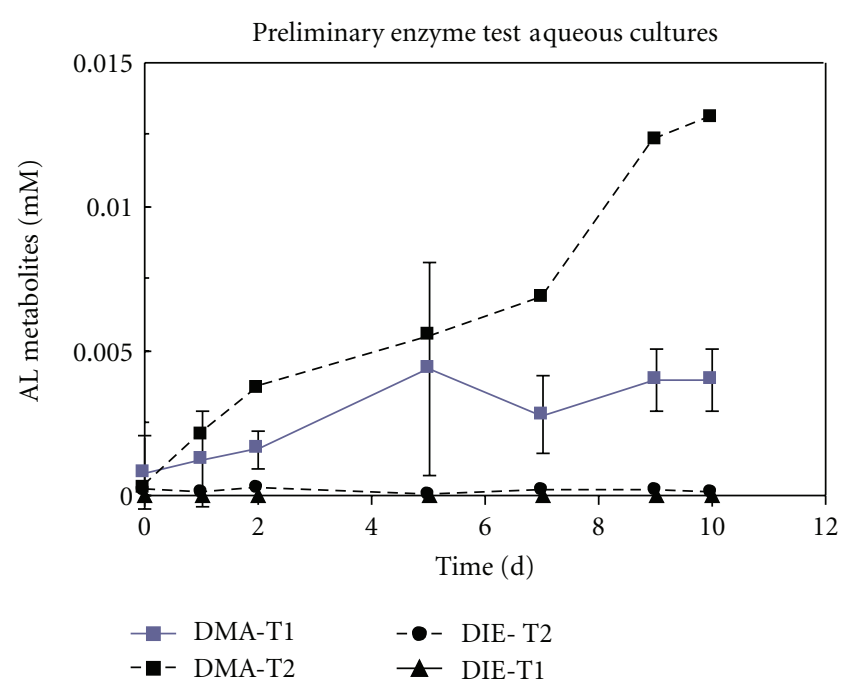

FIGURE 3: Production of alachlor metabolites during preliminary enzyme test in aqueous cultures. Treatment 1 consisted of the EES only and Treatment 2 consisted of the EES and $\mathrm{H}_{2} \mathrm{O}_{2}$. DMA $=2$ chloro-2' $6^{\prime}$-diethylacetamilide, DIE $=2,6$-diethylanaline.

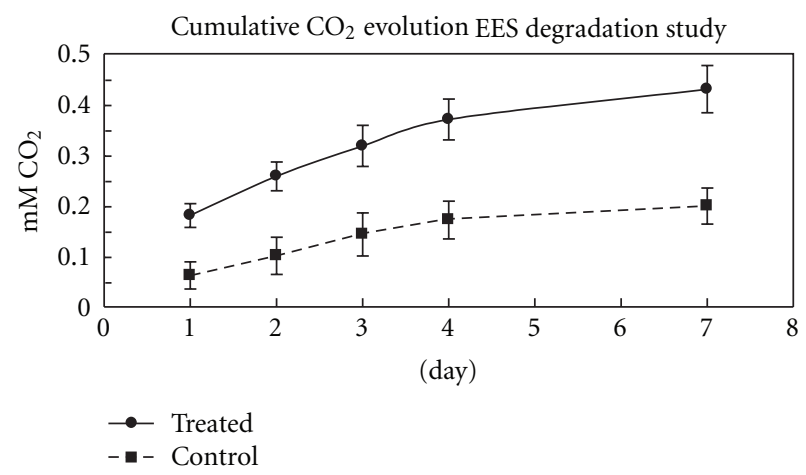

FIgURE 4: Evolution of $\mathrm{CO}_{2}$ during the incubation period of the soil degradation study, which assessed the degradative ability of the EES applied to pesticide-contaminated soil. Cumulative evolution of $\mathrm{CO}_{2}$ in treated and control biometers. Values are the average of 9 samples. Error bars represent 1 standard deviation.

$\left.0.0223 \mathrm{mM} \mathrm{CO}_{2} \mathrm{~d}^{-1}\right)$. The total amount of $\mathrm{CO}_{2}$ evolved from the treatment biometers was significantly different from the control biometers according to the Kruskal-Wallis one-way analysis of variance on ranks $(P<0.001)$. The rate of $\mathrm{CO}_{2}$ produced during the first 3 days of incubation was approximately two times greater than the overall evolution rate $\left(0.0687 \mathrm{mM} \mathrm{d}^{-1}\right)$.

3.2.2. Herbicide Degradation. During the incubation period, atrazine concentration decreased from an initial concentration of $0.730 \pm 0.091 \mathrm{mM}$ to a final concentration of $0.4891 \pm 0.011 \mathrm{mM}$. A $15 \%$ decrease in AT concentration was seen by the first day after treatment with the EES. As seen in Figure 5(a), AT degradation continued for another day at which time no additional AT was degraded. No significant degradation was seen in the control biometer flasks.
Assuming a pseudo first-order reaction for the disappearance of AT, the plot of the natural logarithm of initialized AT concentration $\left(\mathrm{C} / \mathrm{C}_{\mathrm{o}}\right)$ versus time yielded the first-order rate constant of $0.0882 \mathrm{~d}^{-1}$. The half-life $\left(t_{1 / 2}\right)$ for AT calculated from the plot was 8.0 days.

During the incubation period, alachlor concentration decreased from an initial concentration of $0.640 \pm 0.125 \mathrm{mM}$ to a final concentration of $0.297 \pm 0.075 \mathrm{mM}$. Compared to AT, the initial disappearance of AL proceeded at a faster rate and resulted in a greater amount of $\mathrm{AL}$ transformed. A 35\% decrease in AL concentration was seen by the first day after treatment with the EES. As seen in Figure 5(b), $\mathrm{AL}$ degradation continued for another day at which point no additional AL was degraded. No significant degradation was seen in the control biometer flasks. Assuming a pseudo first-order reaction for the disappearance of $\mathrm{AL}$, the plot of the natural logarithm of initialized AL concentration $\left(\mathrm{C} / \mathrm{C}_{\mathrm{o}}\right)$ versus time yielded the first-order rate constant of $0.2504 \mathrm{~d}^{-1}$. The half-life $\left(t_{1 / 2}\right)$ for AL calculated from the plot was 3.0 days.

There were no significant changes in metabolite concentrations within the control biometer flasks. All of the monitored AT metabolites except atrazine deethyl-2-hydroxy were seen in the treated biometer flasks (Figure 6(a)). Within 24 hours, all metabolites detected exhibited an increase in concentration except for hydroxyatrazine (OEIT; Figure 6(b)). The most extensive changes occurred with the dealkylated metabolites. Deethylatrazine (CAIT) exhibited the greatest increase on day one and then slowly decreased in concentration until day 3 , at which point no further change was seen. The bis-dealkylated metabolite (CAAT) and deisopropylatrazine (CEAT) showed a similar change in concentration increasing until day 3 . The double dealkylated metabolite increased once again before the concentration slowly decreased whereas CEAT exhibited a decrease in concentration from day 3 until the end of the incubation period.

Alachlor degradation resulted in the formation of the 2-chloro-2',6'-diethylacetanilide (DMA) and 2,6-diethylaniline (DIE) (Figure 7). Initially there was an increase in DMA but by day 2 the concentration began to decrease. A slight increase was seen at day 4 at which point no further change was seen. There was a slow increase in DIE until day 2 and then the concentration gradually decrease until day 4 at which point the concentration remained the same. The change in the DIE metabolite was minimal throughout the incubation period.

\section{Discussion}

4.1. $A T$ and $A L$ Biodegradation in Aqueous Cultures. In both enzyme treatments there was an immediate decrease in the concentration of both AT and AL. The amount of decrease was approximately equal for both treatments. Within $24 \mathrm{hr}$, however, the treatment with both the EES and $\mathrm{H}_{2} \mathrm{O}_{2}$ exhibited a greater decrease in AT and AL. The $\mathrm{H}_{2} \mathrm{O}_{2}$ activated the ligninolytic enzymes resulting in a greater production of hydroxy radicals available for further oxidations. 


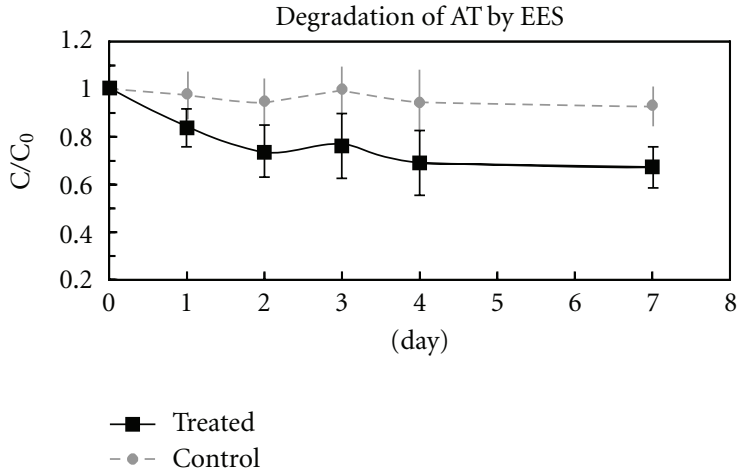

(a)

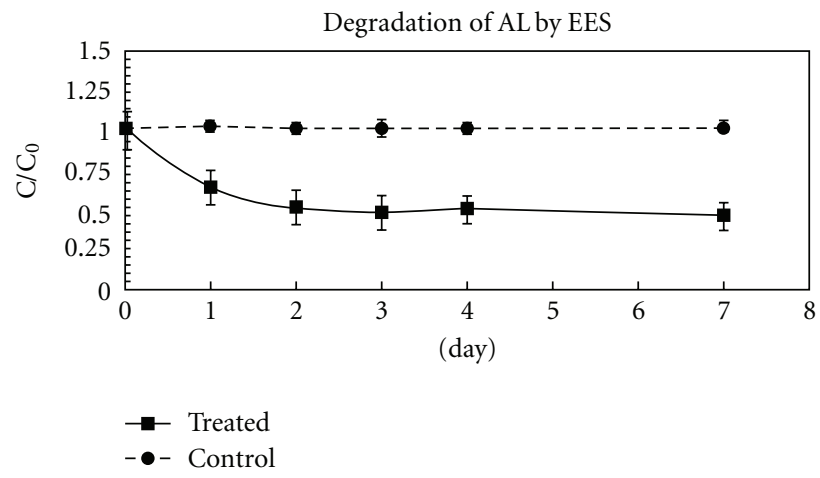

(b)

FIgure 5: Disappearance of AT and AL over time from biometers of the EES degradation study. Data are the means of triplicate experiments. Error bars represent \pm 1 standard deviation. (a) Atrazine concentration (C) is initialized and expressed as a fraction of the initial concentration $\left(\mathrm{C}_{0}\right)$. (b) Alachlor concentration $(\mathrm{C})$ is initialized and expressed as a fraction of the initial concentration $\left(\mathrm{C}_{0}\right)$.

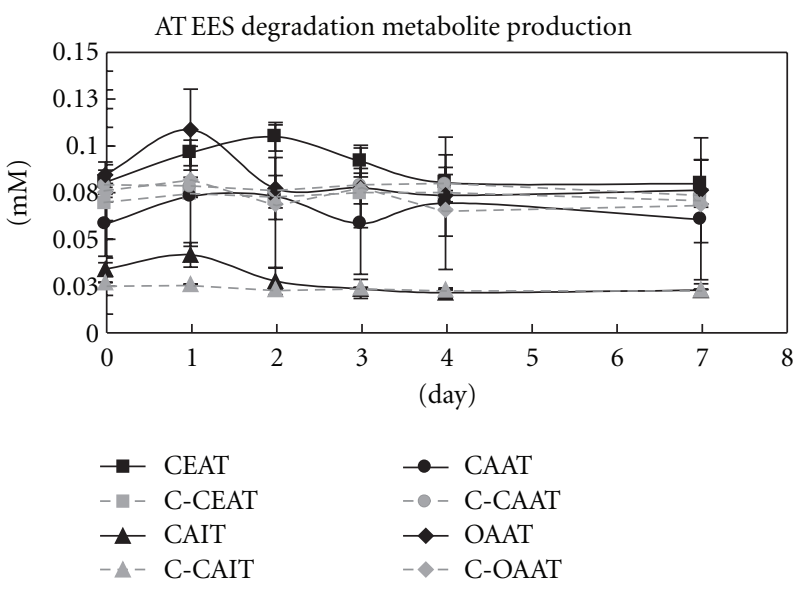

(a)

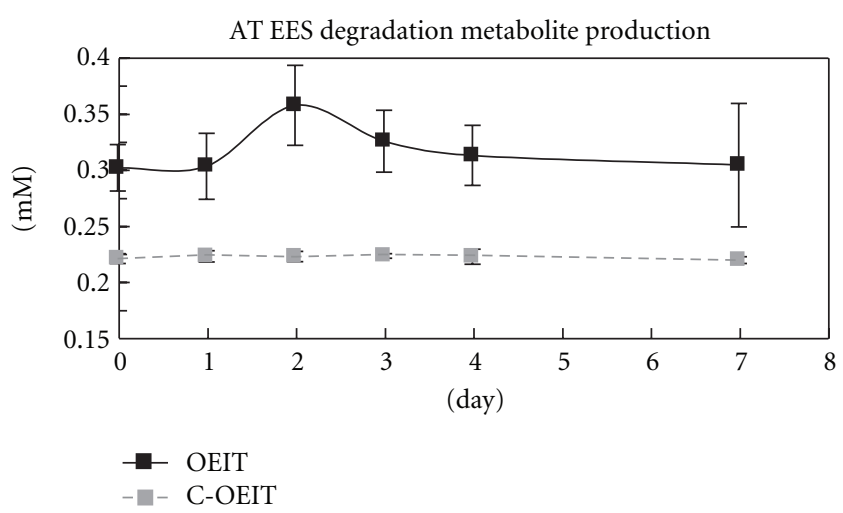

(b)

FIGURE 6: Production of atrazine metabolites over time in the EES degradation study. Metabolites found in control biometers (C-metabolite) are indicated by corresponding dotted lines. (a) All metabolites detected except for OEIT. (b) Hydroxyatrazine detected in biometer flasks. Numbers are the average of 9 values. Error bars represent one standard deviation of triplicate experiments.

The degradation of AT in both treatments resulted in the production of the dealkylated metabolites. The EES alone produced primarily deisopropyl atrazine (CEAT). Addition of $\mathrm{H}_{2} \mathrm{O}_{2}$ increased the production of all metabolites and caused the transformation of the initial metabolites to the bis-dealkylated products (CAAT, OAAT). These results are similar to those of Arnold et al. [18] in which the major products detected were the chlorinated metabolites, CAAT and CEAT. Only $5.8 \%$ of the AT was transformed to the dechlorinated metabolites. In reaction mixtures with higher concentration of $\mathrm{H}_{2} \mathrm{O}_{2}$, the dealkylation reaction was favored producing less dechlorinated products. Sequential batch treatments resulted in further transformation of the dealkylated products to the dechlorinated forms. In this work, very few dechlorinated products were formed and the treatment without $\mathrm{H}_{2} \mathrm{O}_{2}$ had more hydroxyatrazine produced. In Arnold et al.'s work [18], oxidation of the alkyl side chains occurred as well.
Both of the AL metabolites were detected in the reaction flasks. There was a greater amount of 2-chloro- $2^{\prime}, 6^{\prime}-$ diethylacetamilide (DMA) formed in Treatment 2 (EES and $\mathrm{H}_{2} \mathrm{O}_{2}$ ). The 2,6-diethylaniline (DIE) metabolite was detected in Treatment 2 only. In general, the amount of metabolites detected was very low. This suggested that the 2 products analyzed for were further degraded and thus did not accumulate within the reaction flasks. In the treatment flasks, analysis of the culture solution detected several unidentified peaks that may be further degradation products of the $\mathrm{AL}$ metabolites, DMA and DIE.

4.2. AT and AL Biodegradation in Soil Microcosms. Treatment of the pesticide-contaminated mix-load site soil with the extracellular enzyme solution resulted in degradation of $32 \%$ and $54 \%$ of the AT and AL, respectively. However, complete removal of the metabolites from the soil was not accomplished (Table 3 ). Catabolic activity occurred steadily 
throughout the incubation period, while the net $\mathrm{CO}_{2}$ evolved $(0.2308 \mathrm{mM})$ indicated that approximately $12.2 \%$ of the AT and $4.0 \%$ of the $\mathrm{Al}$ was completely mineralized. Other studies with the white rot fungi have shown mineralization of both AT and AL. In work investigating several white rot fungi, Ferrey et al. [19] found that the fungi were able to mineralize the aromatic carbon (C) of $\mathrm{AL}$ to $\mathrm{CO}_{2}$. After 122 days, $P$. chrysosporium mineralized approximately $6 \%$ of the alachlor $\left(\mathrm{C}_{0}=18 \mathrm{mgl}^{-1}\right)$. Transformation also resulted in partially degraded metabolites, $37 \%$ in the aqueous fraction and $25 \%$ associated with the wood solids. In another study, $48 \%$ of AT in aqueous cultures was transformed by P. chrysosporium [20]. In an experiment utilizing ${ }^{14} \mathrm{C}$-labeled AT, approximately $24 \%$ of the initial radioactivity from the side chain (ethyl) carbons was transformed to $\mathrm{CO}_{2}$ by day 16 of the incubation period ( $18 \%$ of the total AT initially present). Very little of the ring Cs were mineralized to $\mathrm{CO}_{2}$. However, the previous research was conducted with the fungus and isolated compounds in cultures containing no soil. The results from this research suggested that interactions of the transformation products with the complex nature of the mix-load site soil reduced the amount of net $\mathrm{CO}_{2}$ produced. The nature of the fungal enzyme system produced free radicals, which could become involved in coupling reactions within the soil resulting in precipitates and/or binding of the transformation products to soil organic matter. In the work by Mougin et al. [20], 30\% of the transformation products were immobilized bound residues. Many substituted anilines, especially chlorinated moieties, have been shown to strongly bind to soil humic substances [4]. Therefore the probability that a portion of the AL metabolites formed in these experiments became bound to the soil was great. Streptomyces sp and P. chrysosporium were reported to transform AT in contaminated soil with $30 \%$ immobilized by production of bound residues. Therefore, a portion of the degraded AT might have become bound to the soil. The dechlorinated metabolite, OEIT, has been shown to bind to soil at a greater extent than AT itself. Thus, the disappearance of OEIT in the biometers might have been the result of bound residue formation.

Another enigma encountered in this research was the nature of the interaction of the EES with soil components (mineral and organic). Adsorption or immobilization of enzymes on mineral colloids has affected their stability positively by enhancing their activity or negatively by inhibiting the activity of the protein molecules [21]. Changes induced in the EES through reactions with soil components might have resulted in the production of more bound residues. Immobilization of laccase onto soil mediated the transformation of guaiacol, 1-naphthol, and 4-chloro-1naphthol into oligomeric products by $\mathrm{C}-\mathrm{C}$ and $\mathrm{C}-\mathrm{O}$ coupling reactions [21].

The rate constant for AT and AL biodegradation was determined to be $0.0882 \mathrm{~d}^{-1}$ and $0.2504 \mathrm{~d}^{-1}$, respectively. These rates of AT and AL disappearance are considerably faster than the degradation by a selected microbial consortium isolated from the contaminated mix-load site soil [11]. The ligninolytic enzyme kinetic system is different than other microbial enzymes in that enzyme-substrate complexes are

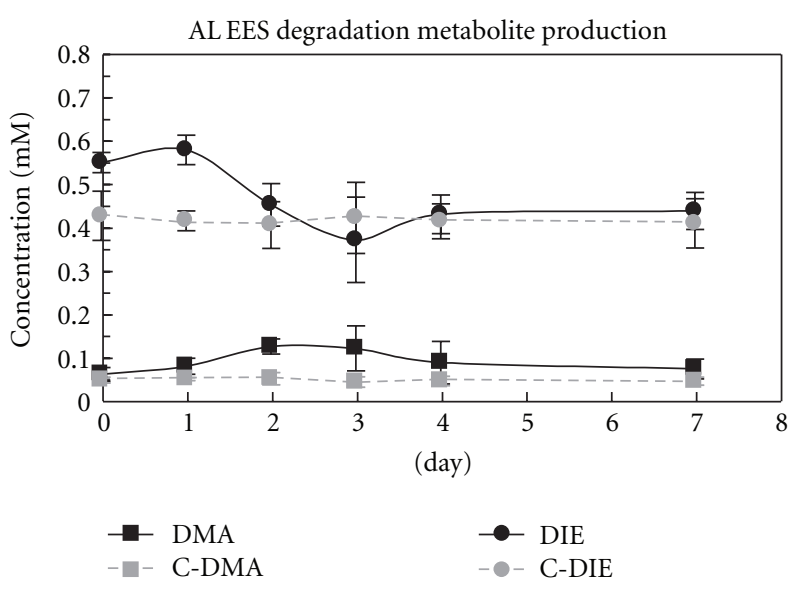

FIGURE 7: Production of alachlor metabolites over time in the EES degradation study. Numbers are the average of 9 values. Error bars represent one standard deviation of triplicate experiments.

not detected. Peroxidase activity is described as irreversible ping-pong kinetics; the enzyme and substrate must collide and form the covalently bound complex. The rate at which the complex reacts is fast compared to the rate in which it dissociates and thus reverts to the initial reactants. The result is that the rate of reaction appears to have no upper limit; that is, the greater the concentration of reactants the faster the reaction [22]. Thus, peroxidase enzymes exhibited a simpler steady-state rate equation. Overall, free radical mediated processes generally followed pseudo first-order kinetics [23]. These faster reaction rates were typical of the ligninolytic enzyme system.

Other rate data for reactions of peroxidases with AT and AL was limited in the literature, but comparisons were made to photolytic reactions. During indirect and direct photolysis of a substrate, the adsorption of UV-visible light energy resulted in the formation of oxidants such as the hydroxy radical $(\mathrm{XOH})$ [24], causing similar reactions as described above. The observed rates constants calculated from firstorder rate plots were $0.0960 \mathrm{~d}^{-1}$ and $0.6960 \mathrm{~d}^{-1}$ for direct and indirect photolysis. In the indirect process, the $\mathrm{XOH}$ are formed faster, thus the faster degradation rate [24]. This rate was similar to that calculated from the current research data, $\left(0.0882 \mathrm{~d}^{-1}\right.$ versus $\left.0.0960 \mathrm{~d}^{-1}\right)$.

Direct photocatalysis ( $350 \mathrm{~nm}$ ) of AL in aqueous solution resulted in a degradation rate of $7.14 \mathrm{~d}^{-1}$ [25]. Compared to this research work, the direct photocatalysis rate was exceedingly fast. However, the presence of soil constituents would have decreased degradation rates due to the scavenging of the free radicals produced by the EES. In the EES research work, the rate of degradation of AL was still almost 3 times as fast as the rate of AT disappearance. Considering the high oxidative state of the s-triazine ring, $\mathrm{AL}$ was a more attractive substrate for the oxidative reactions initiated by the EES. In fact, small methoxylated nonphenolic aromatics such as AL have served as crucial substrates for LiP [26]. Bollag et al. [27] found rapid dimerization of the AL metabolite, DIE, with the humic material, syringic acid. Thus, the disappearance 
TABLE 3: Overview of AT and AL transformation and of the production and further transformation of metabolites within the EES-treated soil. (a) AT transformation. (b) AL transformation and the $\mathrm{Net}^{\mathrm{CO}_{2}}$ evolved during incubation.

(a)

\begin{tabular}{lcc}
\hline$\%$ AT removed & \multicolumn{2}{c}{ mM AT removed } \\
\hline 32.3 & & 0.2359 \\
\hline Metabolite & Formed (mM) & Degraded (mM) \\
\hline CEAT & 0.0242 & 0.0240 \\
CAAT & 0.0258 & 0.0234 \\
OIET & 0.0432 & 0.0089 \\
OIAT & 0.0 & 0.0 \\
OAAT & 0.0269 & 0.0355 \\
CAIT & 0.0089 & 0.0202 \\
\hline Total & 0.1290 & 0.1120 \\
\hline
\end{tabular}

(b)

\begin{tabular}{lcc}
\hline$\%$ AL removed & \multicolumn{2}{c}{ mM AL removed } \\
\hline 53.5 & & 0.3424 \\
\hline Metabolite & Formed $(\mathrm{mM})$ & Degraded (mM) \\
\hline DMA & 0.1252 & 0.0517 \\
DIE & 0.0957 & 0.2074 \\
\hline Total & 0.2209 & 0.2591 \\
\hline Net $\mathrm{CO}_{2}$ evolution $(\mathrm{mM})$ & & \\
\hline 0.2308 & & \\
\hline
\end{tabular}

of DIE in the biometers could have been the result of dimerization. Rapid transformation of AL in the EES-treated soil paralleled the processes outlined in the literature.

4.2.1. Metabolite Production and Degradation. For AT, the hydroxylated metabolites tended to accumulate in the biometer flasks without further transformation, while the dealkylated metabolites were further transformed. The increase in the dechlorinated $\mathrm{N}$-dealkylated metabolites before the increase in hydroxyatrazine suggested that dechlorination of both atrazine and the double dealkylated metabolite occurred. There was a greater amount of deisopropyl atrazine (CEAT) present in the soil than deethyl atrazine (CAIT) indicating that reaction with the isopropyl side chain was favored over reaction with the ethyl side chain of AT.

In a study of AT degradation by the WRF, Pleurotus pulmonarius, in microcosms with spent mushroom substrate (SMS), both chlorinated and nonchlorinated metabolites were seen [28]. The monodealkylated chlorinated metabolites, CAIT and CEAT, were produced the fastest and reached higher concentrations during the first 2 weeks. They were quickly transformed and did not accumulate in the treated microcosms. The dechlorinated metabolites, especially OAAT, were not seen until later in the incubation period. All of the hydroxylated metabolites were seen during the later stages of the incubation period. These results were similar to the transformation of metabolites measured in the biometers even though the fungal enzyme solution without the fungus was used for herbicide degradation. One difference was that hydroxyatrazine (OEIT) was not found as a metabolite in the EES-treated biometer flasks. This was probably due to the fact that the use of the EES increased the transformation rates of metabolites. An increase in the dechlorinated N-dealkylated metabolite (OAAT) occurred early in the experiment. Since there was an additional subsequent increase in OAAT that coincided with an increase in hydroxyatrazine (OEIT), the initial increase in OAAT suggested that the OAAT formed early in the incubation period was derived from bis-N-dealkylated metabolite (CAAT) rather than OEIT. The low concentration of CAAT compared to CEAT and CAIT was additional evidence of this conclusion. In the work by Mougin et al. [20], both hydroxylated and/or N-dealkylated metabolites were also found supporting the theory that the enzymatic combustion process initiated by the EES produced free radicals that could attach to multiple sites on the AT molecule. The formation of these many compounds during the degradation of AT illustrated the complexity of the EES catalytic process and suggested the existence of many degradation routes that resulted in complex interconnected pathways.

Alachlor degradation resulted in the formation of DMA and DIE, but only DMA was further transformed. The lack of correlation between the amounts of DMA and DIE transformed suggested that other reactions within the soil system were involved in the transformation of DIE. The increase in DMA coincided with a gradual decrease in DIE indicating that transformation of both metabolites occurred simultaneously. The significant difference between the initial DIE concentration in the treated flasks and in the control flasks suggested that degradation occurred very rapidly with 
further transformation of DIE as the rate-limiting step. There was a greater amount of both DIE and DMA in the soil degradation study than in the EES-treated aqueous cultures. As with the degradation of AT, the presence of soil components hindered further transformation of the $\mathrm{AL}$ metabolites through the formation of bound residues.

\section{Conclusions}

Treatment of a highly contaminated mix-load site soil with fungal enzymes resulted in the degradation of the herbicides, atrazine, and alachlor. Some mineralization of both herbicides occurred during incubation; however, metabolites of both AT and AL were detected within the treated soil. Degradation of the metabolites also occurred during incubation, indicating that treatment with fungal enzymes can be a viable option in the remediation of contaminated soils.

The presence of other contaminants within the soil did not inhibit AT and AL degradation. In fact, other herbicides present in the soil were also degraded during the study. However, the high concentrations of these other compounds may have reduced the amount of degradation of the target herbicides, AT and AL. Multiple applications of the EES may result in further degradation of all herbicides present in the mix-load site soil. More research on the ability of the EES to react with multiple substrates is warranted.

\section{References}

[1] A. E. M. Chirnside, W. F. Ritter, and M. Radosevich, "Isolation of a selected microbial consortium from a pesticidecontaminated mix-load site soil capable of degrading the herbicides atrazine and alachlor," Soil Biology and Biochemistry, vol. 39, no. 12, pp. 3056-3065, 2007.

[2] J. Gan, R. L. Becker, W. C. Koskinen, and D. D. Buhler, "Degradation of atrazine in two soils as a function of concentration," Journal of Environmental Quality, vol. 25, no. 5, pp. 1064-1072, 1996.

[3] W. R. Roy, S. F. J. Chou, and I. G. Krapac, "Off-site movement of pesticide-contaminated fill from agrichemical facilities during the 1993 flooding in Illinois," Journal of Environmental Quality, vol. 24, no. 5, pp. 1034-1038, 1995.

[4] S. E. Maloney, "Pesticide degradation in fungi," in Bioremediation, G. M. Gadd, Ed., British Mycological Society Symposium Series 23, pp. 188-223, Cambridge University Press, Cambridge, UK, 2001.

[5] R. A. Ames and B. L. Hoyle, "Biodegradation and mineralization of atrazine in shallow subsurface sediments from Illinois," Journal of Environmental Quality, vol. 28, no. 5, pp. 16741681, 1999.

[6] C. A. Reddy and Z. Mathew, "Bioremediation with white rot fungi," in Fungi in Bioremediation, G. M. Gadd, Ed., British Mycological Society Symposium Series 23, pp. 52-78, Cambridge University Press, Cambridge, UK, 2001.

[7] I. Singleton and Z. Mathew, "Fungal remediation of soils contaminated with persistent organic pollutants," in Fungi in Bioremediation, G. M. Gadd, Ed., British Mycological Society Symposium Series 23, pp. 79-96, Cambridge University Press, Cambridge, UK, 2001.
[8] D. P. Barr and S. D. Aust, "Mechanisms white rot fungi use to degrade pollutants," Environmental Science and Technology, vol. 28, no. 2, pp. 78A-87A, 1994.

[9] S. Rodríguez Couto, A. Domínguez, and A. Sanromán, "Utilisation of lignocellulosic wastes for lignin peroxidase production by semi-solid-state cultures of Phanerochaete chrysosporium," Biodegradation, vol. 12, no. 5, pp. 283-289, 2001.

[10] R. Kondo, K. Kurashiki, and K. Sakai, "In vitro bleaching of hardwood kraft pulp by extracellular enzymes excreted from white rot fungi in a cultivation system using a membrane filter," Applied and Environmental Microbiology, vol. 60, no. 3, pp. 921-926, 1994.

[11] A. E. M. Chirnside, W. F. Ritter, and M. Radosevich, "Biodegradation of aged residues of atrazine and alachlor in a mix-load site soil," Soil Biology and Biochemistry, vol. 41, no. 12, pp. 2484-2492, 2009.

[12] J. Xin, M. R. Young, and M. A. Lannan, Baseline Environmental Investigation, Reading Bone Facility, Wik Associates, New Castle, Del, USA, 1995.

[13] G. Feijoo, C. Dosoretz, and J. M. Lema, "Production of lignin peroxidase by Phanerochaete chrysosporium in a packed bed bioreactor operated in semi-continuous mode," Journal of Biotechnology, vol. 42, no. 3, pp. 247-253, 1995.

[14] M. Tien and T. K. Kirk, "Lignin peroxidase of Phanerochaete chrysosporium," Methods in Enzymology, vol. 161, no. C, pp. 238-249, 1988.

[15] A. Paszczyński, R. L. Crawford, and V. B. Huynh, "Manganese peroxidase of Phanerochaete chrysosporium: purification," Methods in Enzymology, vol. 161, pp. 264-270, 1988.

[16] L. M. Zibilske, "Carbon mineralization," in Methods of Soil Analysis, Part 2: Microbiological and Biochemical Properties, R. W. Weaver, S. Angle, P. Bottomley et al., Eds., pp. 850-855, SSSA, Madison, Wis, USA, 1994.

[17] A. E. M. Chirnside and W. F. Ritter, "Development of a solid-phase extraction method for herbicide residue analysis of soil samples," in Application of Agricultural Analysis in Environmental Studies, ASTM STP 1162, American Society for Testing and Materials, Philadelphia, Pa, USA, 1992.

[18] S. M. Arnold, W. J. Hickey, and R. F. Harris, "Degradation of atrazine by Fenton's reagent: condition optimization and product quantification," Environmental Science and Technology, vol. 29, no. 8, pp. 2083-2089, 1995.

[19] M. L. Ferrey, W. C. Koskinen, R. A. Blanchette, and T. A. Burnes, "Mineralization of alachlor by lignin-degrading fungi," Canadian Journal of Microbiology, vol. 40, no. 9, pp. 795-798, 1994.

[20] C. Mougin, C. Laugero, M. Asther, J. Dubroca, P. Frasse, and M. Asther, "Biotransformation of the herbicide atrazine by the white rot fungus Phanerochaete chrysosporium," Applied and Environmental Microbiology, vol. 60, no. 2, pp. 705-708, 1994.

[21] A. Naidja, P. M. Huang, and J. M. Bollag, "Enzyme-clay interactions and their impact on transformations of natural and anthropogenic organic compounds in soil," Journal of Environmental Quality, vol. 29, no. 3, pp. 677-691, 2000.

[22] H. B. Dunford, Heme Peroxidases, Wiley-VCH, New York, NY, USA, 1999.

[23] A. Kindaria and S. D. Aust, "Free radical reactions catalyzed by peroxidases from white rot fungi," in Free Radicals in Biology and Environment, F. Minisci, Ed., pp. 449-465, Kluwer Academic, Dodrecht, The Netherlands, 1997.

[24] A. Torrents, B. G. Anderson, S. Bilboulian, W. E. Johnson, and C. J. Hapeman, "Atrazine photolysis: mechanistic investigations of direct and nitrate- mediated hydroxy radical 
processes and the influence of dissolved organic carbon from the Chesapeake Bay," Environmental Science and Technology, vol. 31, no. 5, pp. 1476-1482, 1997.

[25] C. C. Wong and W. Chu, "The hydrogen peroxide-assisted photocatalytic degradation of alachlor in $\mathrm{TiO} 2$ suspensions," Environmental Science and Technology, vol. 37, no. 10, pp. 2310-2316, 2003.

[26] P. J. Harvey and C. F. Thurston, "The biochemistry of ligninolytic fungi," in Fungi in Bioremediation, G. M. Gadd, Ed., British Mycological Society Symposium Series 23, pp. 2751, Cambridge University Press, Cambridge, UK, 2001.

[27] J. M. Bollag, R. D. Minard, and S. Y. Liu, "Cross-linkage between anilines and phenolic humus constituents," Environmental Science and Technology, vol. 17, no. 2, pp. 72-80, 1983.

[28] S. Masaphy, D. Levanon, and Y. Henis, "Degradation of atrazine by the lignocellulolytic fungus Pleurotus pulmonarius during solid-state fermentation," Bioresource Technology, vol. 56, no. 2-3, pp. 207-214, 1996. 

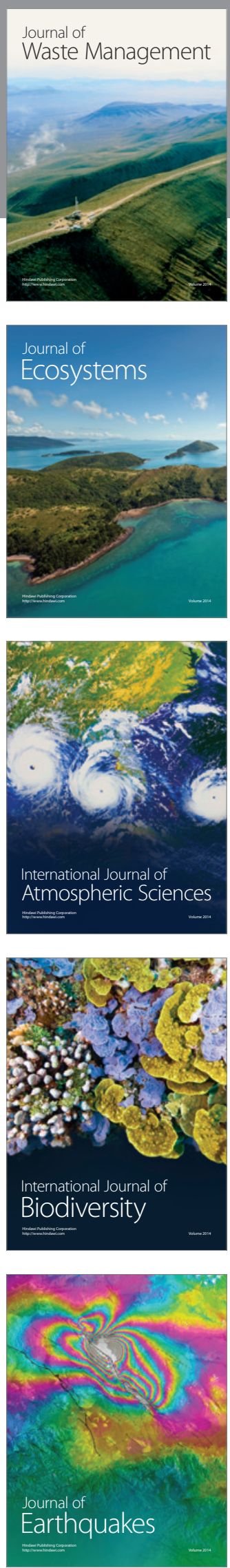
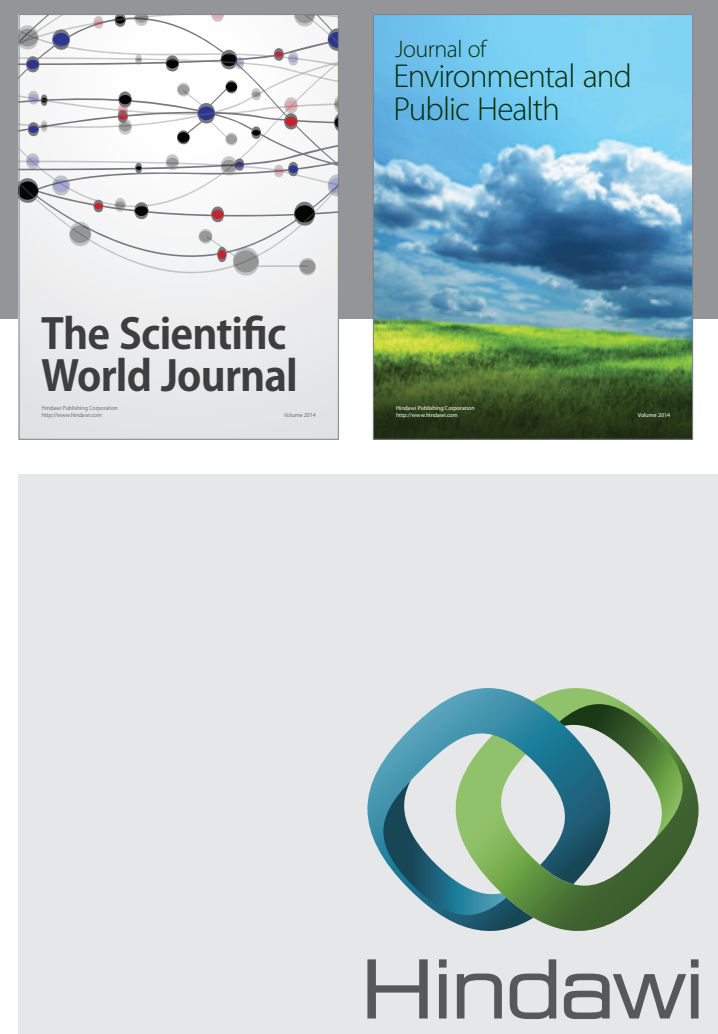

Submit your manuscripts at

http://www.hindawi.com
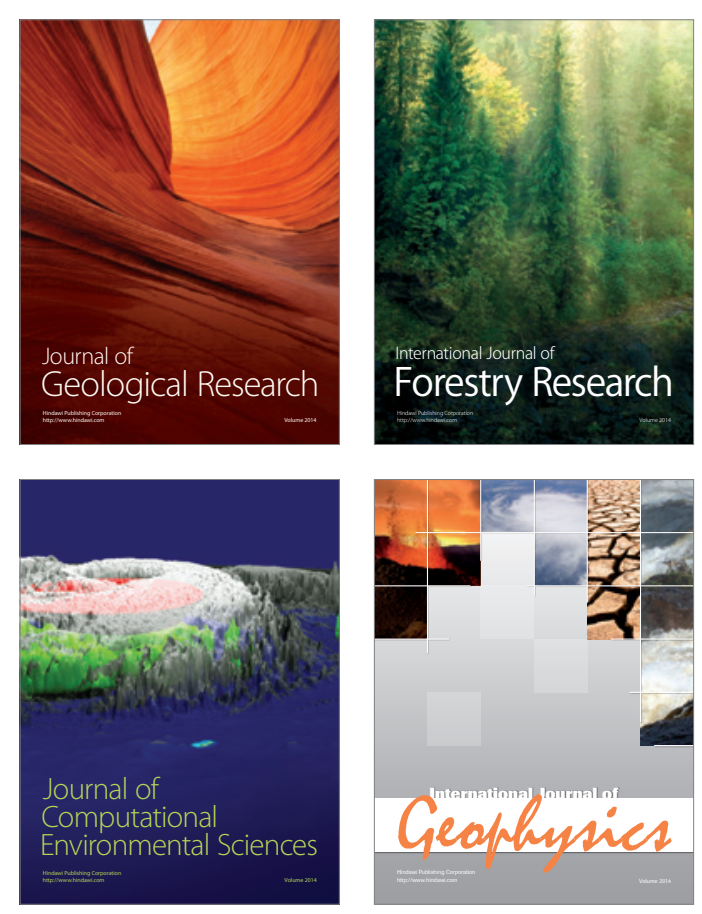
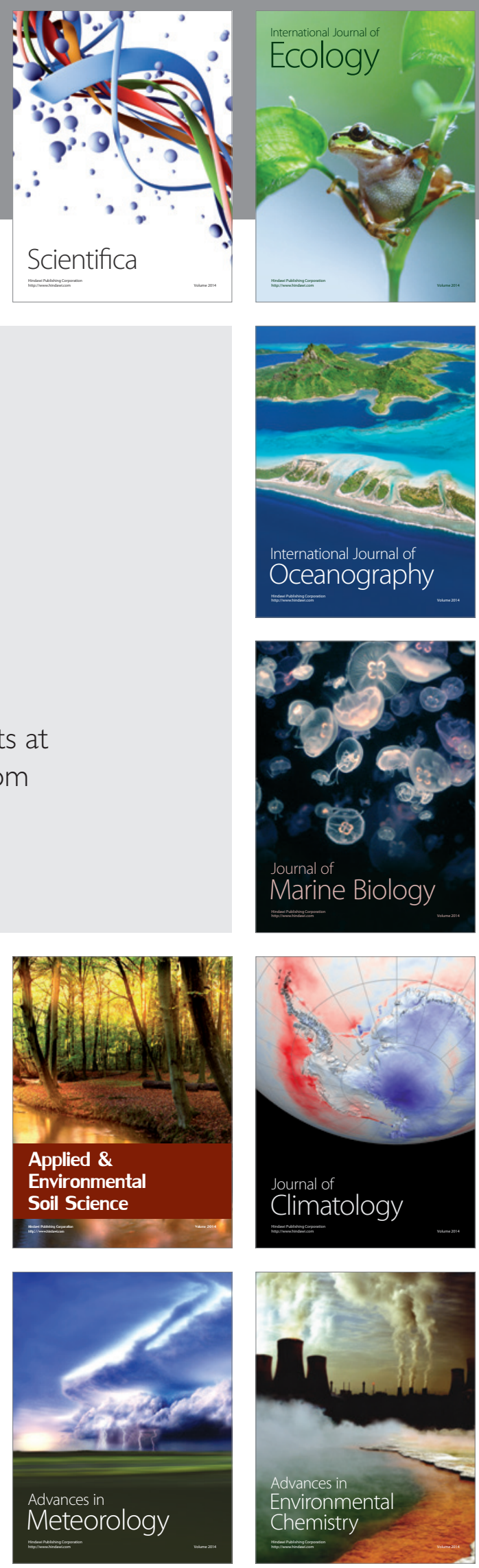